\title{
Percent Recovered Normalized by Weight
}

National Cancer Institute

\section{Source}

National Cancer Institute. Percent Recovered Normalized by Weight. NCI Thesaurus.

Code C92416.

The percentage of the dose that is recovered from the specimen type, from dosing to end of the current collection interval divided by the weight. 